\title{
Total Synthesis of Quinolizidine Alkaloid (-)-217A. Application of Iminoacetonitrile Cycloadditions in Organic Synthesis
}

\author{
Kevin M. Maloney and Rick L. Danheiser \\ Department of Chemistry, Massachusetts Institute of Technology, Cambridge, Massachusetts \\ 02139
}

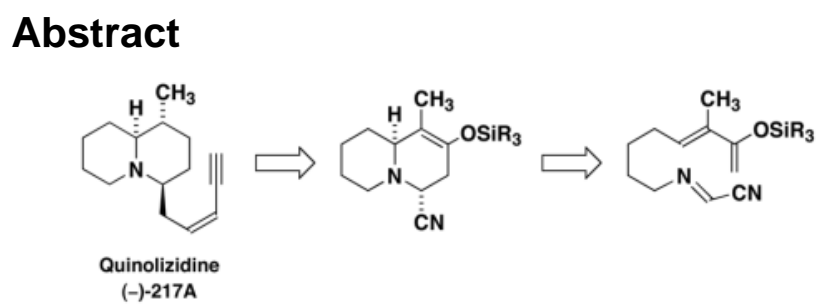

An intramolecular iminoacetonitrile [4 2] cycloaddition functions as the key step in an efficient total synthesis of the quinolizidine alkaloid (-)-217A.

\begin{abstract}
The importance of substituted quinolizidines and indolizidines as synthetic targets is well established. The skeletons of a number of bioactive natural products incorporate these structures, and many of these compounds are available in very limited amounts from their natural source. ${ }^{1}$ Highly toxic quinolizidine and indolizidine alkaloids isolated from the skin of poisonous amphibians have attracted much interest as research tools for neurophysiological investigations, and recently quinolizidine alkaloids obtained from marine sources have been identified as lead compounds for the development of anticancer, antiinflammatory, and cardiovascular drugs. A number of ingenious methods have been developed in response to the synthetic challenge posed by these molecules, and these alkaloids have served as a popular testing ground for methods for the construction of pyrrolidines, piperidines, and various azabicyclic systems. ${ }^{2}$

Recently, we reported a strategy for the synthesis of azabicyclic compounds that should provide the basis for efficient new routes to a variety of substituted indolizidines and quinolizidines. ${ }^{3}$ As outlined in Scheme 1, this strategy involves the intramolecular [4 +2] cycloaddition of a new class of activated imines, ${ }^{4}$ iminoacetonitriles. Iminoacetonitriles are conveniently prepared from alcohols by Mitsunobu coupling with $\mathrm{TfNHCH}_{2} \mathrm{CN}$ followed by elimination of trifluoromethanesulfinate, and readily undergo intramolecular [4 +2] cycloadditions to afford $\alpha$-amino nitriles of general type $2 .^{3,5}$ The utility of $\alpha$-amino nitriles as versatile intermediates for the synthesis of substituted nitrogen heterocycles is well documented. ${ }^{6}$ Metalation provides opportunities for alkylation and other carbon-carbon bond-forming processes, while exposure to Lewis acids furnishes iminium ions which can be intercepted with Grignard reagents (i.e., $\mathbf{2} \rightarrow \mathbf{4}$, the "Bruylants reaction") or engaged in a variety of other useful carbon-carbon bond forming reactions. Stereoelectronic effects
\end{abstract}

danheisr@mit.edu.

Supporting Information Available: Experimental procedures and characterization data for all new compounds. This material is available free of charge via the Internet at http://pubs.acs.org. 
control the outcome of these transformations (vide infra), allowing for the stereoselective elaboration of cycloadducts as outlined in Scheme 1,3,6

In order to further test and refine this methodology, we have undertaken the synthesis of several bioactive quinolizidine alkaloids such as clavepictine (5), ${ }^{7,8}$ halichlorine (6), ${ }^{9,10}$ and alkaloid 217A (7). ${ }^{11}$ Herein we report the application of the iminoacetonitrile cycloaddition as a key step in the total synthesis of quinolizidine (-)-217A, an amphibian alkaloid isolated by Daly in 1993 from skin extracts of the Madagascan frog Mantella baroni. Previously, elegant total syntheses of quinolizidine 217A have been reported by the groups of Pearson and Panek. ${ }^{12}$ Our goal was the development of an approach to the synthesis of quinolizidine $217 \mathrm{~A}$ considerably more efficient than these earlier syntheses, and capable of supporting the preparation of significant quantities of the target alkaloid.

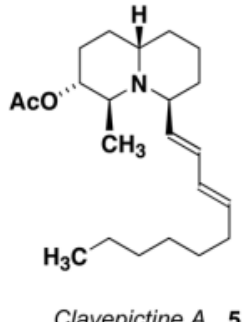

Clavepictine A $\mathbf{5}$

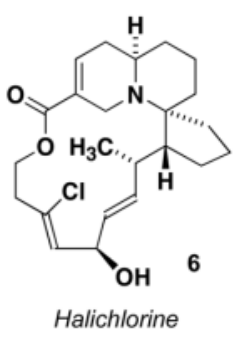

Halichlorine

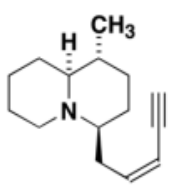

7

Quinolizidine 217A

Scheme 2 outlines our retrosynthetic strategy, which features the intramolecular iminoacetonitrile cycloaddition $\mathbf{1 0} \rightarrow \mathbf{9}$ as a pivotal step. Alkylation of $\mathbf{9}$ would then be employed to install the enynylmethyl side chain, and stereoelectronic control in the subsequent reductive decyanation step was expected to deliver the desired stereochemistry at C-4. Control of the stereochemistry at C-1 would be established by epimerization of the ketone intermediate $\mathbf{8}$ derived from the silyl enol ether cycloadduct. In this first generation synthesis, we elected to employ resolution to provide access to the natural (-)-isomer as well as the unnatural isomer, deferring for future study the possibility of employing chiral Lewis acids to catalyze an asymmetric version of the cycloaddition. This decision was also influenced by the fact that for the synthesis of more complex targets such as $\mathbf{5}$ and $\mathbf{6}$, we envisioned strategies involving chiral cycloaddition substrates in which the stereogenic centers in the "connecting tether" would dictate the stereochemical outcome of the reaction.

Our first synthetic subgoal was the development of an efficient route to cycloaddition substrate 10. Based on our previous studies, we anticipated that $\mathbf{1 0}$ would be available from sulfonamide 16 by elimination of sulfinate on exposure to a weak base such as carbonate. Scheme 3 outlines our efficient 4 -step route to 16. Mitsunobu coupling ${ }^{13}$ of commercially available 5-hexenol (11) with $\mathrm{TfNHCH}_{2} \mathrm{CN}$ provided the expected sulfonamide, and ozonolysis then furnished aldehyde $\mathbf{1 3}$ in excellent yield. Wittig olefination of $\mathbf{1 3}$ using the acylphosphorane $14^{14}$ produced the desired $(E)$ - $\alpha, \beta$-unsaturated ketone 15 in $85-87 \%$ yield after purification by column chromatography. ${ }^{15}$ Finally, conversion to the desired enol ether was achieved using the general procedure of Dunogues et al. ${ }^{16}$ to afford $\mathbf{1 6}$ in excellent yield after purification by column chromatography on acetone-deactivated silica gel. Attempts to employ a cross-metathesis strategy ${ }^{17}$ for the conversion of $\mathbf{1 2}$ to 15 by reaction with 3methyl-3-buten-2-one were frustrated by the homodimerization of $\mathbf{1 2}$, which produced a dimer unreactive in secondary metathesis.

As shown in Scheme 4, exposure of $\mathbf{1 6}$ to the action of cesium carbonate led to the elimination of trifluoromethanesulfinate and formation of iminoacetonitrile $\mathbf{1 0}$ as the expected mixture of $E$ and $Z$ imine isomers. The stereochemistry of this intermediate is not crucial, as we have previously demonstrated that iminoacetonitrile isomers interconvert 
under the conditions of the $[4+2]$ cycloaddition. ${ }^{3}$ In the event, heating iminoacetonitrile $\mathbf{1 0}$ at $130{ }^{\circ} \mathrm{C}$ for $36 \mathrm{~h}$ produced the desired $\alpha$-amino nitrile 9 in good yield. Addition of BHT was found to be beneficial in suppressing decomposition of the desired product. As expected, the isomer with an exo-oriented (axial) cyano group was isolated as the exclusive product of the reaction as a consequence of the " $\alpha$-amino nitrile anomeric effect."

For the next stage of the synthesis, alkylation of $\alpha$-amino nitrile $\mathbf{9}$, we initially focused our attention on the enynylmethyl compounds $\mathbf{1 7}, \mathbf{1 8}, \mathbf{1 9}$, and $\mathbf{2 0} .{ }^{19}$ Surprisingly, the desired enyne $\mathbf{2 1}$ was obtained at best in only $30 \%$ overall yield after reductive decyanation (Scheme 5). Although alkylation with model alkylating agents such as allyl bromide proceeded smoothly, complex mixtures resulted from the reaction of 9 with enynylmethyl derivatives 17-20. Although we have been unable to characterize any of the byproducts of this reaction, we speculate that electron transfer to the enynylmethyl halide from the metalated nitrile (thus generating a capto-dative stabilized amino nitrile radical) may be complicating this alkylation. ${ }^{20}$ We therefore turned our attention to a less unsaturated allylic halide, (Z)-3-bromo-1-chloropropene, with the idea of later elaborating the full enyne moiety via a Sonogashira coupling reaction.

In the event, we were pleased to find that alkylation of 9 with (Z)-3-bromo-1-chloropropene proceeded cleanly, and reductive decyanation of the crude alkylation product with sodium cyanoborohydride then afforded the desired quinolizidine 22 in $74-77 \%$ overall yield (Scheme 6). As predicted, axial delivery of hydride to the intermediate iminium ion leads to the formation of the desired diastereomer as the exclusive product of the reaction. ${ }^{21}$

Treatment of silyl enol ether $\mathbf{2 2}$ with 1.1 equiv of $n-\mathrm{Bu}_{4} \mathrm{NF}$ in THF then generated ketone $\mathbf{2 3}$ as a single diastereomer with the $\mathrm{C}-1$ methyl group in the desired equatorial orientation. Finally, resolution of quinolizidine ( \pm )-23 using $(R)-(-)-1,1^{\prime}$-binaphthyl-2,2'-diylphosphoric $\operatorname{acid}^{22}$ provided enantiomerically pure (-)-23 in $44 \%$ overall yield from the racemate.

The last stage of the synthesis, involving reductive excision of the carbonyl group and Sonogashira coupling, proved unexpectedly difficult. Initial attempts to effect deoxygenation of ketone $\mathbf{2 3}$ (as well as derivatives of the corresponding alcohol) were complicated by the formation of a byproduct ultimately identified as the tricylic amine $\mathbf{2 4} .^{23}$ Since this side product appeared to arise from cyclization of C-2 radical intermediates onto the vinyl chloride appendage, we focused our attention on strategies in which the reduction step could be carried out in the presence of efficient hydrogen atom transfer agents so as to more effectively intercept the intermediate radical prior to cyclization. Success was finally achieved by means of the one-pot protocol outlined in Scheme 7.

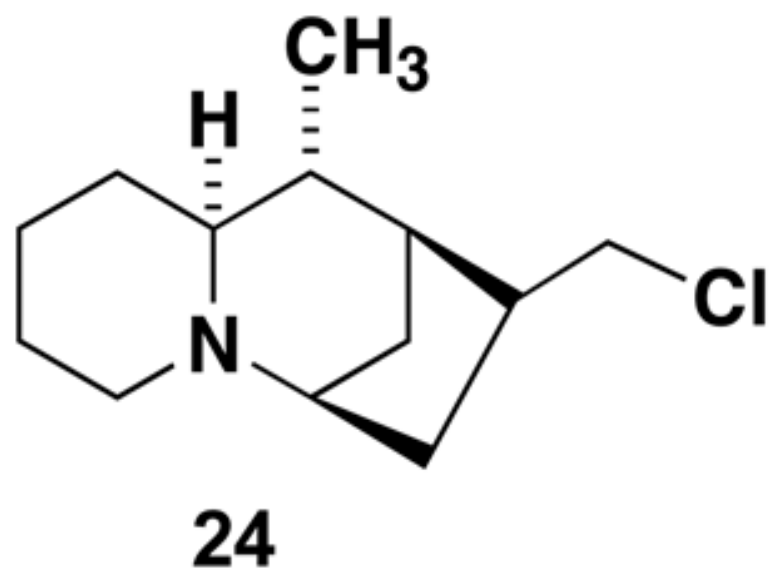

Org Lett. Author manuscript; available in PMC 2011 October 28. 
Thus, reduction of the tosylhydrazone derivative of (-)-23 with $\mathrm{NaBH}_{3} \mathrm{CN}$ in the presence of excess $t$-butyl mercaptan completely suppressed the undesired radical cyclization and furnished vinyl chloride 26 in 63-66\% overall yield. Sonogashira coupling with trimethylsilylacetylene proceeded smoothly, provided that the acetylene was added slowly to suppress competing alkyne dimerization. Finally, desilylation with $\mathrm{K}_{2} \mathrm{CO}_{3}$ in methanol afforded quinolizidine (-)-217A (7) $\left([\alpha]^{22} \mathrm{D}-14\left(c 0.8, \mathrm{CHCl}_{3}\right)\right.$, lit. ${ }^{12}[\alpha]^{20} \mathrm{D}-13.75(c 0.4$, $\left.\mathrm{CHCl}_{3}\right)$ ) with spectral characteristics identical with those reported for the natural product. ${ }^{11,12}$

In summary, the intramolecular iminoacetonitrile [4 +2] cycloaddition functions as a key step in an efficient assembly of the quinolizidine core of the amphibian alkaloid (-)-217A, enabling the total synthesis of this natural product in only 12 steps. The application of iminoacetonitrile cycloadditions in the synthesis of other bioactive alkaloids is under investigation.

\section{Supplementary Material}

Refer to Web version on PubMed Central for supplementary material.

\section{Acknowledgments}

We thank the National Institutes of Health (GM 28273) and Merck Research Laboratories for generous financial support. K. M. M. was supported in part by NIH Training Grant CA 09112.

\section{References}

1. For a recent review of the chemistry and biology of indolizidine and quinolizidine alkaloids, see Daly JW, Garraffo HM, Spande TF. Pelletier SW. Alkaloids: Chemical and Biological Perspectives. PergamonNew York1999; 13:1-161.

2. Reviews: (a)Michael JP. Cordell GA. The Alkaloids. Academic PressNew York2001; 55:91-258.(b) Michael JP. Nat Prod Rep. 2004; 21:625. [PubMed: 15459758] and references cited therein.

3. Amos DT, Renslo AR, Danheiser RL. J Am Chem Soc. 2003; 125:4970. [PubMed: 12708834]

4. For reviews of imino Diels-Alder reactions, see (a) Heintzelman GR, Meigh IR, Mahajan YR, Weinreb SM. Org React. 2005; 65:141.(b) Buonora P, Olsen JC, Oh T. Tetrahedron. 2001; 57:6099. (c) Tietze LF, Kettschau G. Top Curr Chem. 1997; 189:1.(d)Boger DL, Weinreb SM. Hetero DielsAlder Methodology in Organic Synthesis. Academic PressSan Diego1987

5. For a theoretical study of the iminoacetonitrile Diels-Alder reaction, see Su M-D. Organometallics. 2004; 23:2507.

6. Reviews: (a) Enders D, Shilvock JP. Chem Soc Rev. 2000; 29:359.(b)Rubiralta M, Giralt E, Diez A. Piperidine: Structure, Preparation, Reactivity, and Synthetic Applications of Piperidine and its Derivatives. ElsevierAmsterdam1991:225-312.(c) Husson HP, Royer J. Chem Soc Rev. 1999; 28:383.

7. Isolation and anticancer activity: Raub MF, Cardellina JH II, Choudhary MI, Ni C-Z, Clardy J, Alley MC. J Am Chem Soc. 1991; 113:3178.

8. Synthetic studies: (a) Toyooka N, Yotsui Y, Yoshida T, Momose T, Nemoto H. Tetrahedron. 1999; 55:15209.(b) Ha JD, Cha JK. J Am Chem Soc. 1999; 121:10012.

9. Isolation and activity as inhibitor of vascular cell adhesion molecule-1: Kuramoto M, Tong C, Yamada K, Chiba T, Hayashi Y, Uemura D. Tetrahedron Lett. 1996; 37:3867.

10. Synthetic studies: (a) Trauner D, Schwarz JB, Danishefsky SJ. Angew Chem, Int Ed. 1999; 38:3542.(b) Matsumura Y, Aoyagi S, Kibayashi C. Org Lett. 2004; 6:965. [PubMed: 15012076]

11. (a) Garrafo HM, Caceres J, Daly JW, Spande TF, Andriamaharavo NR, Andriantsiferana M. J Nat Prod. 1993; 56:1016. [PubMed: 8377013] (b) Jain P, Garraffo HM, Yeh HJC, Spande TF, Daly JW, Andriamaharavo NR. J Nat Prod. 1996; 59:1174. [PubMed: 8988603] 
12. Previous syntheses of quinolizidine 217A required 19-21 steps; see (a) Pearson WH, Suga H. J Org Chem. 1998; 63:9910.(b) Huang H, Spande TF, Panek JS. J Am Chem Soc. 2003; 125:626. [PubMed: 12526650]

13. Reviews: (a) Hughes DL. Org React. 1992; 42:335.(b) Hughes DL. Org Prep Proced Int. 1996; 28:127.

14. Aitken AR, Atherton JI. J Chem Soc, Perkin Trans 1. 1994:1281.

15. The crude product of the Wittig reaction consisted of a 90:10 mixture of $E$ and $Z$ enones.

16. Cazeau P, Duboudin F, Moulines F, Babot O, Dunogues J. Tetrahedron. 1987; 43:2075.

17. (a) Connon SJ, Blechert S. Angew Chem, Int Ed. 2003; 42:1900.(b) Chatterjee AK, Choi TL, Sanders DP, Grubbs RH. J Am Chem Soc. 2003; 125:11360. [PubMed: 16220959]

18. Bonin M, Romero JR, Grierson DS, Husson HP. J Org Chem. 1984; 49:2392.

19. These alkylating agents were prepared from the corresponding alcohol (Hartung IV, Eggert U, Haustedt LO, Niess B, Schafer PM, Martin H, Hoffmann R. Synthesis. 2003:1844.as described previously: for 17 and 20, see Feldman KS. Tetrahedron Lett. 1982; 23:3031.For 18 and 19, see Tsushima K, Murai A. Tetrahedron Lett. 1992; 33:4345.

20. Other conceivable side reactions include deprotonation of the enynylmethyl halide and addition of the lithiated nitrile to the enyne moiety. For examples of the metalation of allylic halides, see Julia M, Verpeaux JN, Zahneisen T. Synlett. 1990:769.For addition of organolithium compounds to conjugated enynes, see Brandsma L. Synthesis of Acetylenes, Allenes, and Cumulenes. ElsevierOxford2004:74.

21. Approach of hydride in this fashion maintains maximal orbital overlap between the incoming nucleophile and the developing lone pair on nitrogen. For a discussion of stereoelectronic control in nucleophilic additions to cyclic iminium ions, see (a)Deslongchamps P. Stereoelectronic Effects in Organic Chemistry. PergamonNew York1983:211-221.(b) Stevens RV. Acc Chem Res. 1984; 17:289.

22. (a) Jacques J, Fouquey C. Tetrahedron Lett. 1971; 12:4617.(b) Imhof R, Kyburz E, Daly JJ. J Med Chem. 1984; 27:165. [PubMed: 6198519] (c) Tsushima K, Murai A. Tetrahedron Lett. 1992; 33:4345.

23. The tricyclic amine was isolated as a single diastereomer (stereochemistry of the chloromethyl substituent not assigned). 


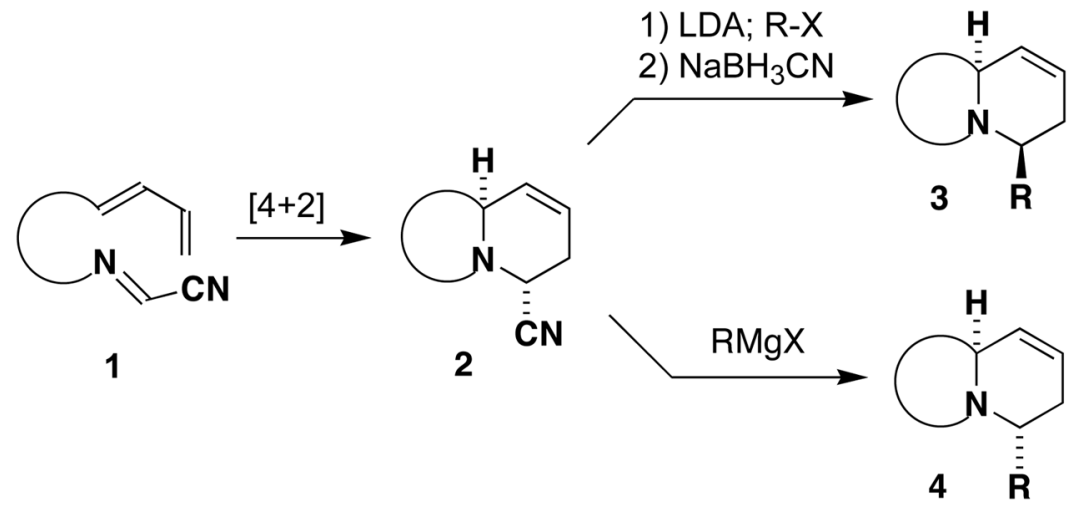

Scheme 1.

Org Lett. Author manuscript; available in PMC 2011 October 28. 


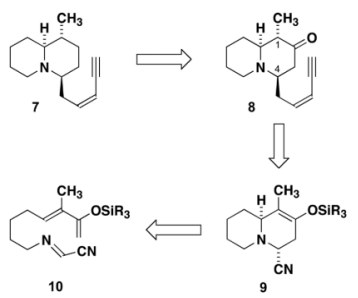

Scheme 2.

Org Lett. Author manuscript; available in PMC 2011 October 28. 


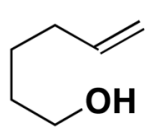

11

1) 1.0 equiv $\mathrm{TfNHCH}_{2} \mathrm{CN}$

1.2 equiv $\mathrm{Ph}_{3} \mathrm{P}$-DIAD
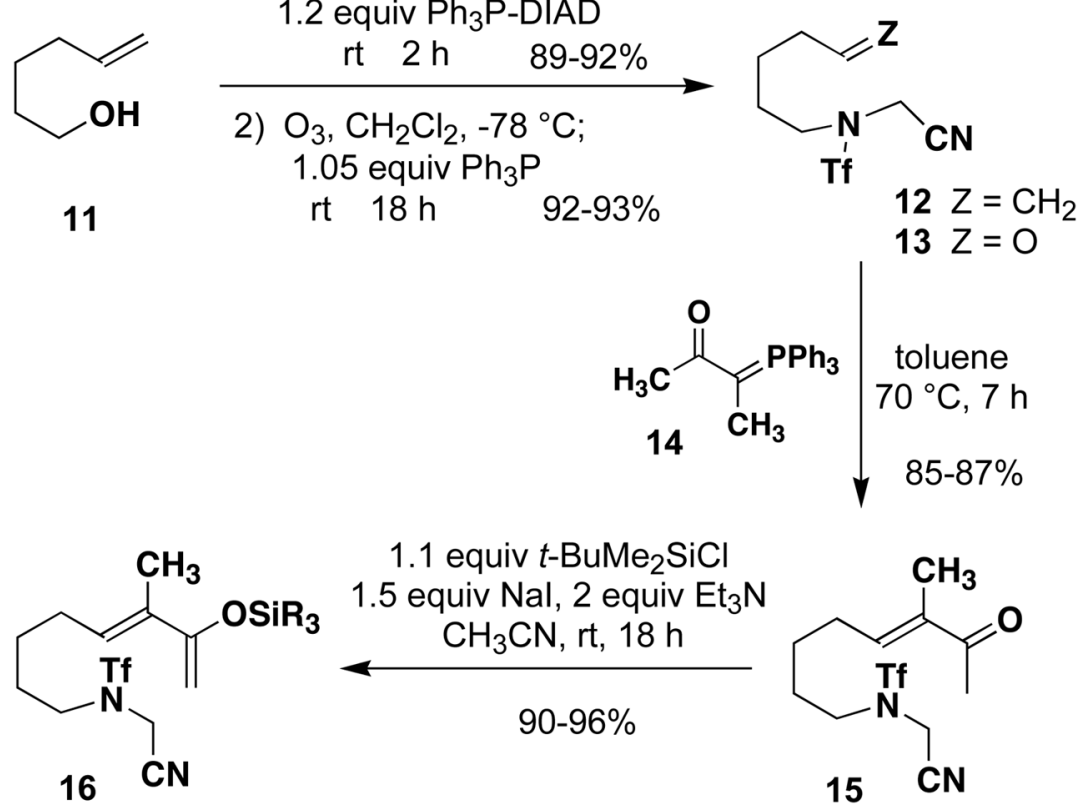

1.1 equiv $t$-BuMe ${ }_{2} \mathrm{SiCl}$
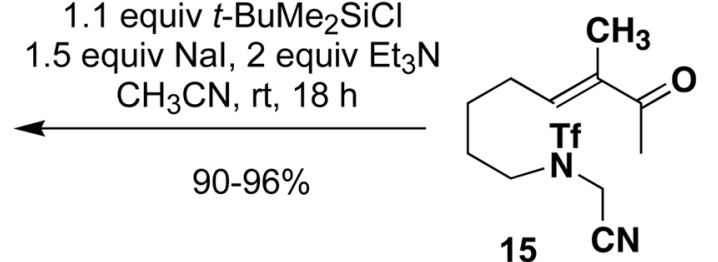

Scheme 3. 


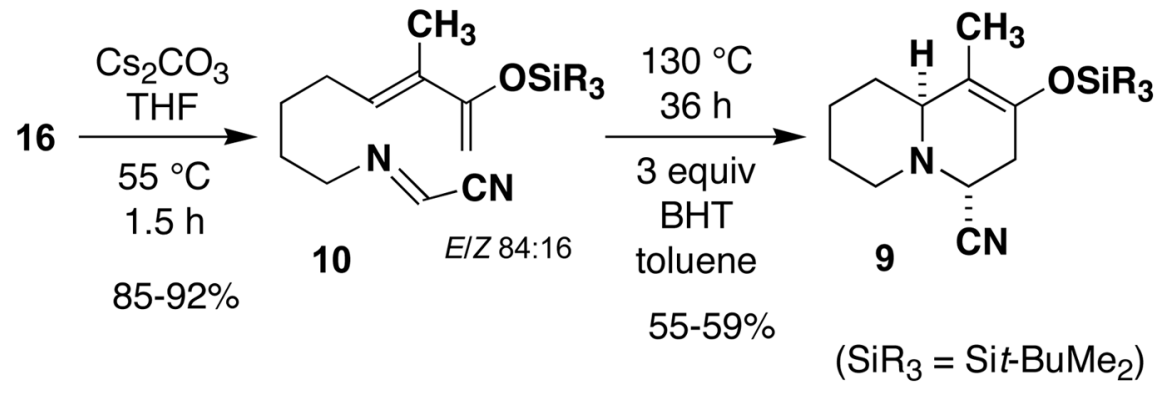

Scheme 4. 
1) LDA, THF

$18,-78^{\circ} \mathrm{C}, 1.5 \mathrm{~h}$

2) $\mathrm{NaBH}_{3} \mathrm{CN}, \mathrm{AcOH}$

$\mathrm{CH}_{3} \mathrm{CN}$, rt, $2 \mathrm{~h}$<smiles></smiles>

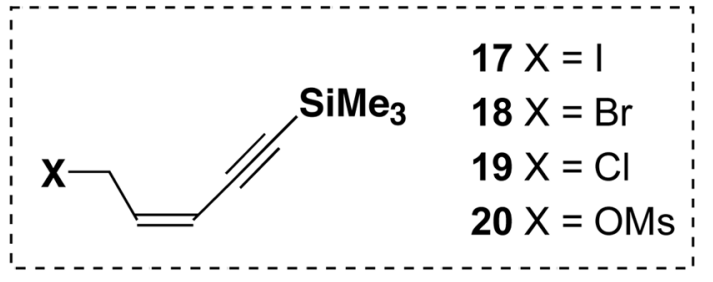

21

Scheme 5. 


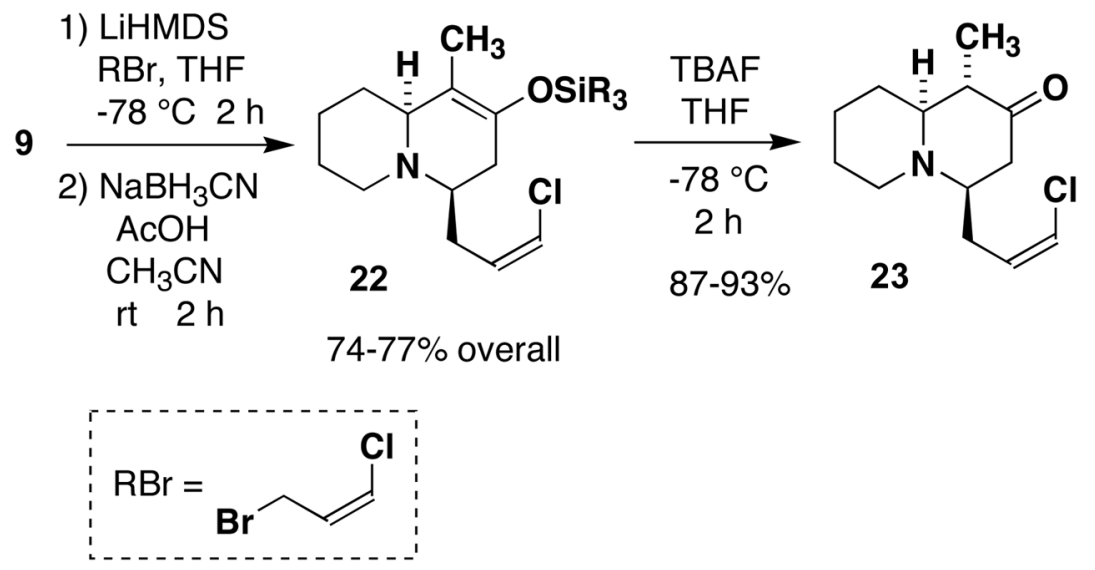

Scheme 6. 


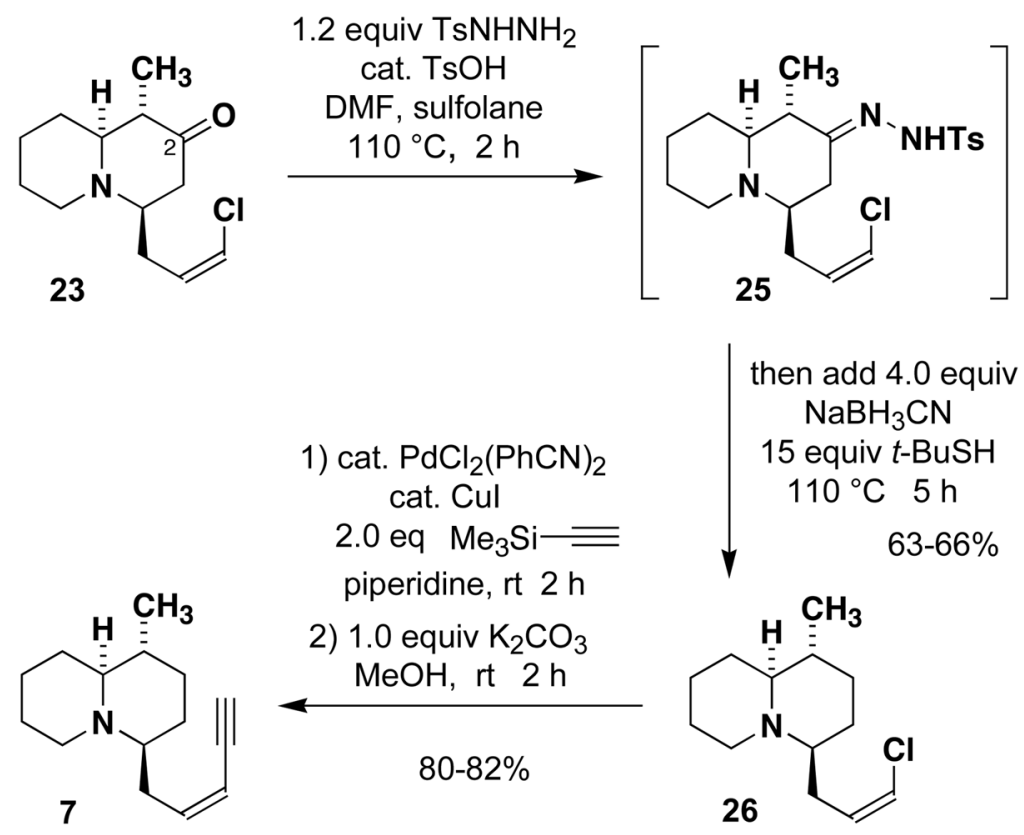

Scheme 7. 